\title{
Hubungan Antara Perilaku Makan dan Citra Tubuh dengan Status Gizi Remaja Putri Usia 15-18 Tahun
}

\section{Relationship between Eating Behavior and Body Image with Nutritional Status of Adolescent Girl Age 15-18 Years}

\author{
Alivia Norma Yusintha*, Adriyanto ${ }^{1}$
}

\begin{abstract}
ABSTRAK
Latar Belakang: Di Indonesia, masalah gizi kurang dan gizi lebih adalah masalah yang masih sering terjadi di usia remaja terutama pada remaja putri. Banyak faktor yang menentukan status gizi remaja putri seperti perilaku makan dan citra tubuh. Perubahan perilaku makan pada remaja putri dikarenakan mereka memiliki citra tubuh yang negatif. Remaja putri ingin memiliki tubuh yang tinggi dan langsing.

Tujuan: Penelitian ini dilakukan untuk menganalisis hubungan antara perilaku makan dan citra tubuh dengan status gizi remaja putri usia 15-18 tahun.

Metode: Penelitian ini adalah observasional analitik menggunakan studi cross sectional pada 93 remaja putri yang dipilih secara simple random sampling. Data yang dikumpulkan adalah terkait perilaku makan yang diperoleh melalui wawancara dengan menggunakan kuesioner Adolescent Food Habit Checklist (AFHC), citra tubuh yang diperoleh melalui wawancara dengan menggunakan kuesioner Body Shape Questionnaire (BSQ), dan data antropometri meliputi berat badan dan tinggi badan.

Hasil: Hasil penelitian ini menunjukkan sebagian besar remaja putri memiliki perilaku makan yang baik $(57 \%)$, citra tubuh positif $(80,6 \%)$, dan status gizi normal $(72 \%)$. Terdapat hubungan antara perilaku makan $(p=0,013)$ dan citra tubuh $(p=0,002)$ dengan status gizi remaja putri usia $15-18$ tahun. Kesimpulan: Remaja putri yang memiliki perilaku makan yang baik dan citra tubuh positif memiliki status gizi yang baik. Remaja putri diharapkan dapat menjalani perilaku makan yang baik seperti membiasakan sarapan dan sering mengonsumsi sayur dan buah agar tercipta status gizi yang baik pula.
\end{abstract}

Kata Kunci: citra tubuh, perilaku makan, remaja putri, status gizi 


\section{ABSTRACT}

Background: In Indonesia, underweight and overweight is a problem that is still common in adolescent girl. Many factors that determine the nutritional status of adolescent girl such as eating behavior and body image. Changes in eating behavior in adolescent girl are caused they have a negative body image. Adolescent girl want to have a tall and slim body.

Objective: This study was conducted to analyze the relationship between eating behavior and body image with nutritional status of adolescent girl aged 15-18 years.

Methods: This study was an observational analytic study using cross sectional design on 93 adolescent girl who selected by simple random sampling. The data were collected using an Adolescent' Food Habit Checklist (AFHC) questionnaire, body image generated using a Body Shape Questionnaire (BSQ) questionnaire, and anthropometric data.

Results: The results showed that most adolescent girl had good eating behavior ((57\%), positive body image (80.6\%), and normal nutritional status (72\%). There was a relationship between eating behavior ( $p=0.013)$ and body image ( $p=0.002)$ with nutritional status of adolescent girl.

Conclusion: Adolescent girl who have good eating behavior and positive body image have good nutritional status. Adolescent girl are expected to serve out good eating behavior such as getting breakfast and often consume vegetables and fruits to create a good nutritional status as well.

Keywords: body image, eating behavior, adolescent girl, nutritional status

\footnotetext{
*Koresponden:

aliviayushinta@gmail.com

${ }^{1}$ Akademi Gizi Surabaya
}

\section{PENDAHULUAN}

Masalah gizi pada remaja masih banyak terjadi di Indonesia, baik gizi kurang maupun gizi lebih. ${ }^{1}$ Hasil dari Riset Kesehatan Dasar pada tahun 2013 menunjukkan bahwa prevalensi remaja yang status gizinya kurus secara nasional sebesar $9,4 \%$ sedangkan prevalensi gemuk pada remaja sebesar $7,3 \%$.

Remaja adalah transisi dari anak-anak menuju ke dewasa. Masa ini merupakan masa terpenting di dalam kehidupan. Di masa ini, terjadi pertumbuhan maupun perubahan biologis diantaranya pematangan seksual, peningkatan berat dan tinggi badan. Perubahan bentuk juga ukuran tubuh dapat menyebabkan remaja memiliki citra tubuh dan gangguan makan. ${ }^{2}$ Proses pertumbuhan dan perkembangan yang pesat terjadi di masa remaja sehingga energi juga zat gizi diperlukan oleh tubuh dalam jumlah yang banyak. Masalah gizi sangat rentan terjadi pada remaja dikarenakan gaya hidup yang salah karena sebagian remaja putri memiliki keinginan agar tubuhnya sesuai dengan yang diinginkan yaitu dapat langsing dan tinggi. ${ }^{3} \mathrm{Hal}$ ini mengakibatkan remaja puri melakukan perubahan perilaku makan yang tidak sehat agar tercapainya bentuk tubuh yang dikehendaki sehingga membawa dampak negatif salah satunya yaitu tidak seimbangnya asupan gizi yang masuk ke dalam tubuh dengan kecukupan gizi yang dianjurkan. ${ }^{4}$ Selain itu, masalah gizi rentan terjadi karena aktivitas remaja menjadi lebih besar dibandingkan pada saat masih kanak-kanak, tetapi energi yang masuk tidak sebanding dengan energi yang dikeluarkan. ${ }^{5}$ Kebutuhan gizi remaja relative besar karena remaja sedang mengalami masa pertumbuhan sehingga dianjurkan untuk mengonsumsi beraneka ragam makanan. ${ }^{6}$

Remaja sudah terbiasa memilih apa saja makanan yang disukainya dan tidak 
bergantung pada orang tua. ${ }^{7}$ Kurannya pengetahuan remaja tentang perilaku makan yang sehat juga menyebabkan remaja cenderung memiliki perilaku makan yang tidak baik. Selain itu, remaja terutama remaja putri cepat bereaksi bahkan agresif pada gangguan atau dorongan dari luar yang mempengaruhinya. ${ }^{8} \quad$ Remaja seringkali mempunyai keinginan untuk diterima oleh teman sebayanya dan juga menarik lawan jenis, sehingga remaja putri cenderung memiliki citra tubuh yang negative. ${ }^{9}$ Yang disebut dengan citra tubuh adalah kumpulan sikap individu yang disadari dan tidak disadari terhadap tubuhnya termasuk persepsi serta perasaan masa lalu dan sekarang tentang bentuk, ukuran, kegunaan, penampilan, dan kemampuan. ${ }^{10}$ Citra tubuh meninggalkan sebuah konsep tentang keadaan tubuh yang ideal yang akan berakibat pada citra tubuh negatif lebih khususnya kepada wanita. ${ }^{11}$ Banyak sekali akibat dari citra tubuh negatif ini, diantaranya remaja putri mulai mempunyai persepsi mengenai citra tubuh dan berusaha untuk menjaga penampilan dengan cara berdiet dan tidak memperhatikan kaidah gizi dan kesehatan sehingga berpengaruh pula terhadap perilaku makan mereka. ${ }^{12}$ Selain itu, tidak sedikit remaja putri yang mulai membatasi pola makannya karena takut gemuk. Sebaliknya, gaya hidup yang tidak sehat dan juga kesadaran yang kurang akan kesehatan membuat sebagian besar remaja putri makan secara berlebihan dan menyebabkan kegemukan. ${ }^{5} \mathrm{Hal}$ ini akan mempengaruhi status gizi remaja putri.

Status gizi adalah suatu ukuran mengenai keadaan tubuh seseorang. ${ }^{13}$ Kebutuhan zat gizi remaja putri harus diperhatikan karena remaja putri masih dalam tahap belajar di sekolah. Jika remaja putri mengalami status gizi yang kurang akan mempengaruhi sistem imunnya sehingga remaja putri lebih mudah menderita penyakit infeksi. Keadaan ini dikhawatirkan akan mempengaruhi kehadiran di sekolah sehingga cenderung tertinggal dalam proses pembelajaran sehingga mempengaruhi prestasi belajar. ${ }^{14}$

Penelitian sebelumnya menunjukkan tidak ada hubungan antara citra tubuh dengan status gizi. ${ }^{15}$ Selain itu, dalam penelitian lainnya juga dijelaskan bahwa tidak ada hubungan perilaku makan dengan status gizi. ${ }^{16}$ Hal tersebut dikarenakan status gizi tidak hanya dipengaruhi oleh citra tubuh tetapi bisa dipengaruhi oleh elemen yang lain seperti asupan makan dan penyakit infeksi. Oleh karena itu, peneliti tertarik untuk meneliti hubungan perilaku makan dan citra tubuh dengan status gizi remaja putri usia 15-18 tahun.

Tujuan penelitian ini adalah untuk menganalisis hubungan perilaku makan dan citra tubuh dengan status gizi remaja putri usia 15-18 tahun.

\section{METODE}

Metode penelitian ini adalah metode observasional analitik dengan menggunakan studi cross sectional. Penelitian ini dilakukan pada bulan Agustus tahun 2017 di Sekolah Menengah Atas Negeri 1 Sidoarjo. Populasi dalam penelitian ini yaitu seluruh siswi Sekolah Menengah Atas Negeri 1 Sidoarjo yang berusia 15-18 tahun. Besar sampel dihitung menggunakan data proporsi Lemeshow dan didapatkan jumlah sampel sebesar 93 orang. Pengambilan sampel ini dilakukan dengan menggunakan simple random sampling. Ada beberapa criteria inklusi dalam penelitian ini, yaitu responden sedang berada di kelas 11 dan 12, berusia 1518 tahun, tidak sedang sakit infeksi/kronis, tidak sedang menjalani diet khusus, dan bersedia menjadi responden dengan menandatangani lembar persetujuan. Pengumpulan data terdiri dari data antropometri yaitu berat badan dan tinggi badan untuk menentukan status gizi berdasarkan Indeks Massa Tubuh (IMT) menurut Umur dengan standar antropometri yang mengacu pada Standar 
World Health Organization (WHO) Tahun 2005, wawancara terkait perilaku makan dengan instrument kuesioner Adolescent' Food Habit Checklist (AFHC) dengan 23 pertanyaan kuesioner AFHC memiliki jawaban ya atau tidak pada pertanyaan yang disediakan. Responden menerima 1 poin jika memiliki respon makanan yang sehat. Skor akhir diperoleh dari jumlah poin yang diterima oleh responden. Setelah skor diperoleh dilakukan pengkategorian yaitu perilaku makan baik jika skor jawaban $\geq$ rata-rata dan tidak baik jika skor jawaban < rata-rata. ${ }^{17}$ Wawancara terkait citra tubuh dengan instrument kuesioner Body Shape Questionnaire (BSQ). Kuesioner ini terdiri dari 34 pertanyaan mengenai bentuk tubuh dan penampilan seseorang selama 4 minggu terakhir. Dalam kuesioner BSQ-34 digunakan skala Likert type ( 1 = tidak pernah, 6 = selalu) untuk mengukur respon dari responden. Skor diperoleh dari penjumlahan keseluruhan item pertanyaan. setelah skor diperoleh, dilakukan pengkategorian yaitu citra tubuh positif jika skor jawaban < 110 dan citra tubuh negatif jika skor jawaban $\geq 110 .{ }^{18}$ Variabel perilaku makan diuji dengan menggunakan uji korelasi spearman karena data yang didapatkan tidak berdistribusi normal sedangkan citra tubuh diuji dengan menggunakan uji korelasi pearson karena data yang didapatkan berdistribusi normal.

\section{HASIL DAN PEMBAHASAN}

Hasil penelitian ini menunjukkan, usia remaja putri berkisar antara 15-18 tahun, remaja putri yang paling banyak menjadi responden adalah remaja putri berusia 16 tahun sebesar $44 \%$, sedangkan remaja putri yang paling sedikit menjadi responden adalah remaja putri yang berusia 18 tahun sebesar $4,3 \%$.

Berdasarkan tabel 1 Sebagian besar remaja putri sudah memiliki perilaku makan yang baik (57\%). Tetapi, presentase ini tidak jauh berbeda dengan remaja putri yang memiliki perilaku makan tidak baik, yaitu sebesar $43 \%$. Banyak remaja putri yang sering meninggalkan waktu sarapan $(50,5 \%)$. Hal ini akan membuat remaja putri merasa lapar pada saat siang hari, sehingga porsi makanan yang dimakan lebih banyak daripada yang seharusnya. ${ }^{3}$ Selain itu, di masa ini remaja sudah bisa memilih makanan yang disukai tanpa melihat bahan apa saja yang terdapat dalam makanan tersebut. Jika keadaan ini dibiarkan, dikhawatirkan akan menyebabkan kegemukan atau obesitas terlebih jika makanan yang dikonsumsinya memiliki kandungan kalori, lemak, dan karbohidrat yang tinggi. ${ }^{19}$ Ada beberapa strategi agar remaja dapat merubah perilaku makannya, salah satunya adalah dengan memperbanyak alternative makanan sehat tetapi dapat menimbulkan selera makan remaja tersebut. ${ }^{20}$

Tabel 1. Distribusi dan Rata-rata Perilaku Makan pada Remaja Putri Usia 1518 Tahun

\begin{tabular}{lcc}
\hline \multicolumn{1}{c}{ Perilaku Makan } & $\mathbf{n}$ & $\mathbf{\%}$ \\
\hline Baik & 53 & 57,0 \\
Tidak Baik & 40 & 43,0 \\
\hline \multicolumn{1}{c}{ Total } & 93 & 100,0 \\
\hline$-\bar{x} \pm S D$ & Min $=2$ & Maks $=17$ \\
$=9,68 \pm 3,904$ & & \\
\hline
\end{tabular}

Sebagian besar remaja putri $(80,6 \%)$ pada tabel 2 sudah memiliki citra tubuh positif. Hal ini sesuai dengan penelitian yang menunjukkan bahwa sebagian besar remaja putri mempunyai citra tubuh positif. ${ }^{21}$ Remaja putri sering mencoba untuk memperhatikan bentuk tubuhnya dengan mengerjakan sesuatu agar penampilan jasmaniahnya terlihat sempurna. Hal ini sering didasari oleh media dan tren yang muncul saat ini. Ketidakpuasan terjadi karena tidak sesuainya bentuk tubuh remaja putri dengan bentuk tubuh yang diinginkannya. ${ }^{22}$

Remaja putri yang mempunyai citra tubuh negatif cenderung memiliki perilaku makan yang tidak baik. Hal ini akan mempengaruhi status gizi remaja putri. Berdasarkan tabel 3 Rata-rata remaja putri yang menjadi responden mempunyai status 
gizi yang baik (72\%). Namun, ada beberapa remaja putri yang masih memiliki status gizi lebih $(19,4 \%)$ dan obesitas $(5,4 \%)$. Hal ini lebih tinggi jika dibandingkan dengan data Riskesdas tahun 2013 yang menyatakan bahwa remaja yang memiliki status gizi gemuk sebesar 7,3\%. Masalah gizi memberikan beberapa dampak buruk pada kesehatan diantaranya malnutrisi yang akan mengacu pada gangguan pertumbuhan dan perkembangan fisik remaja.

Tabel 2. Distribusi dan Rata-rata Citra Tubuh Pada Remaja Putri Usia 15-18

\begin{tabular}{lcc}
\hline \multicolumn{1}{c}{ Citra Tubuh } & $\mathbf{n}$ & $\mathbf{\%}$ \\
\hline Positif & 75 & 80,6 \\
Negatif & 18 & 19,4 \\
\hline \multicolumn{1}{c}{ Total } & 93 & 100,0 \\
\hline $\bar{x} \pm S D$ & Min $=44$ & Maks $=175$ \\
$=88,38 \pm 25,169$ & & \\
\hline
\end{tabular}

Tabel 3. Distribusi dan Rata-rata Status Gizi pada Remaja Putri Usia 15-18 Tahun

\begin{tabular}{lcc}
\hline \multicolumn{1}{c}{ Status Gizi } & $\mathbf{n}$ & $\mathbf{\%}$ \\
\hline Kurus & 3 & 3,2 \\
Normal & 67 & 72,0 \\
Gemuk & 18 & 19,4 \\
Obesitas & 5 & 5,4 \\
\hline \multicolumn{1}{c}{ Total } & 93 & 100,0 \\
\hline$-\bar{x} \pm S D$ & Min $=-2,84$ & Maks $=2,56$ \\
$=0,064 \pm 1,1978$ & & \\
\hline
\end{tabular}

Berdasarkan hasil tabulasi silang pada tabel 4 menunjukkan bahwa beberapa remaja putri yang memiliki perilaku makan yang tidak baik memiliki status gizi yang kurang baik $(22,5 \%)$. Berdasarkan hasil dari uji statistik dengan menggunakan uji korelasi spearman menunjukkan bahwa nilai $p=0,013(p<0,05)$ dan nilai $r=0,256$, yang artinya ada hubungan yang bermakna antara perilaku makan dengan status gizi remaja putri. Hasil penelitian ini didukung oleh penelitian yang menunjukkan bahwa perilaku makan berhubungan dengan status gizi. ${ }^{12}$ Penelitian lain juga menunjukkan bahwa terdapat hubungan yang signifikan antara perilaku makan dengan status gizi. ${ }^{23}$ Sebagian besar remaja putri sangat mencemaskan bentuk tubuhnya dibandingkan dengan makanan yang seharusnya dikonsumsi. Persepsi yang salah tentang perilaku makan akan menyebabkan remaja membatasi asupan makanan yang masuk karena remaja merasa bentuk tubuhnya belum sesuai dengan yang diinginkannya. Selain itu, disamping keinginan untuk diet, kesibukan yang dimiliki oleh remaja seperti kegiatan ekstrakulikuler, pekerjaan rumah, bimbingan belajar, menjadi salah satu alas an remaja untuk meninggalkan waktu makannya khususnya sarapan. Remaja juga sering mengkonsumsi makan makanan cepat saji (fast food) untuk mempersingkat waktu. Perilaku makan sangat berpengaruh terhadap status gizi remaja putri karena perilaku makan yang baik membuat asupan zat gizi yang diperlukan cukup sehingga status gizi remaja putri menjadi lebih baik. Pembatasan konsumsi makanan untuk mendapatkan penampilan fisik yang menunjang justru dapat membahayakan kesehatan remaja sehingga rentan terkena gangguan kesehatan salah satunya seperti anemia. ${ }^{24}$

Berdasarkan hasil tabulasi silang pada tabel 5 menunjukkan bahwa remaja putri yang memiliki citra tubuh negatif tidak hanya remaja putri yang memiliki status gizi lebih, namun juga terjadi pada remaja putri dengan status gizi normal yaitu sebanyak $44,4 \%$. Hal ini menunjukkan bahwa remaja putri masih sering menganggap ukuran tubuhnya masih lebih besar dari ukuran sebenarnya padahal remaja putri sudah memiliki tubuh yang ideal. Berdasarkan hasil dari uji statistic menggunakan uji korelasi pearson didapatkan nilai $p=0,002(p<0,05)$ dan nilai $r=0,315$ yang artinya ada hubungan yang bermakna antara citra tubuh dengan status gizi remaja putri.

Hal ini menujukkan bahwa semakin tinggi ketidakpuasan terhadap citra tubuh, maka status gizinya semakin tidak normal. Hasil penelitian ini didukung dengan penelitian yang menunjukkan bahwa ada hubungan antara citra tubuh dengan status gizi. $^{25}$ 
Tabel 4. Distribusi Perilaku Makan Menurut Status Gizi Remaja Putri Usia 15-18 Tahun

\begin{tabular}{|c|c|c|c|c|c|c|c|c|c|c|c|c|}
\hline \multirow{3}{*}{$\begin{array}{c}\text { Perilaku } \\
\text { Makan }\end{array}$} & \multicolumn{10}{|c|}{ Status Gizi Remaja Putri } & \multirow{3}{*}{ Nilai p } & \multirow{3}{*}{ Nilai } \\
\hline & \multicolumn{2}{|c|}{ Kurus } & \multicolumn{2}{|c|}{ Normal } & \multicolumn{2}{|c|}{ Gemuk } & \multicolumn{2}{|c|}{ Obesitas } & \multicolumn{2}{|c|}{ Total } & & \\
\hline & $\mathrm{n}$ & $\%$ & $\mathbf{n}$ & $\%$ & $n$ & $\%$ & $\mathrm{n}$ & $\%$ & $\mathrm{n}$ & $\%$ & & \\
\hline Perilaku & 1 & 1,9 & 36 & 67,9 & 13 & 24,5 & 3 & 5,7 & 53 & 100,0 & & \\
\hline $\begin{array}{l}\text { Makan } \\
\text { Baik }\end{array}$ & & & & & & & & & & & 0,013 & 0,256 \\
\hline $\begin{array}{l}\text { Perilaku } \\
\text { Makan } \\
\text { Tidak Baik }\end{array}$ & 2 & 5,0 & 31 & 77,5 & 5 & 12,5 & 2 & 5,0 & 40 & 100,0 & & \\
\hline
\end{tabular}

Tabel 5. Distribusi Citra Tubuh Menurut Status Gizi Remaja Putri Usia 15-18 Tahun

\begin{tabular}{|c|c|c|c|c|c|c|c|c|c|c|c|c|}
\hline \multirow{3}{*}{$\begin{array}{l}\text { Citra } \\
\text { Tubuh }\end{array}$} & \multicolumn{10}{|c|}{ Status Gizi Remaja Putri } & \multirow{3}{*}{ Nilai $p$} & \multirow{3}{*}{ Nilai $r$} \\
\hline & \multicolumn{2}{|c|}{ Kurus } & \multicolumn{2}{|c|}{ Normal } & \multicolumn{2}{|c|}{ Gemuk } & \multicolumn{2}{|c|}{ Obesitas } & \multicolumn{2}{|c|}{ Total } & & \\
\hline & $n$ & $\%$ & $n$ & $\%$ & 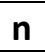 & $\%$ & $\mathrm{n}$ & $\%$ & $n$ & $\%$ & & \\
\hline Citra & 3 & 4,0 & 59 & 78,7 & 9 & 12,0 & 4 & 5,3 & 75 & 100,0 & & \\
\hline $\begin{array}{l}\text { Tubuh } \\
\text { Positif }\end{array}$ & & & & & & & & & & & 0,002 & 0,315 \\
\hline $\begin{array}{l}\text { Citra } \\
\text { Tubuh } \\
\text { Negatif }\end{array}$ & 0 & 0,0 & 8 & 44,4 & 9 & 50,0 & 1 & 5,6 & 18 & 100,0 & & \\
\hline
\end{tabular}

Penelitian lain juga menyatakan bahwa terdapat hubungan antara citra tubuh dengan status gizi. ${ }^{26}$ Ketidakpuasan ini seringkali terjadi karena remaja putri merasa tubuhnya masih terlalu gemuk dan merasa bahwa ada beberapa bagian tubuh yang tidak sesuai dengan ukuran tubuhnya, ketidakpuasan citra tubuh yang dialami oleh remaja putri juga terjadi karena remaja putri mudah untuk terpengaruh dengan media dan tren saat ini. Selain itu, citra tubuh negatif bisa dikarenakan interaksi sosial. Gambaran citra tubuh seseorang muncul saat remaja mulai berinteraksi dengan lingkungan sosialnya atau teman sebaya dan mulai membandingkan dengan teman-teman lainnya. ${ }^{6}$

Selain perilaku makan, citra tubuh negatif juga mengakibatkan remaja putri melakukan berbagai usaha penurunan berat badan dengan cara yang tidak benar dan nantinya akan mempengaruhi status gizinya. ${ }^{19}$

\section{KESIMPULAN}

Remaja dengan perilaku makan dan citra tubuh yang positif cenderung memiliki status gizi yang lebih baik dibandingkan dengan remaja yang memiliki perilaku makan dan citra tubuh yang negatif. Diperlukan adanya usaha dalam membantu dan meningkatkan pengetahuan remaja tentang gizi dan kesehatan. Remaja diharapkan selalu menyempatkan waktu sarapan karena sarapan berfungsi sebagai sumber energi untuk melakukan aktivitas remaja di sekolah. Selain itu, sarapan akan membuat fokus dan konsentrasi belajar meningkat. Perlu dilakukannya penelitian lebih lanjut terkait faktor lain seperti usia, pengetahuan, dan uang jajan yang dapat mempengaruhi status gizi.

\section{ACKNOWLEDGMENT}

Peneliti mengucapkan terima kasih kepada Sekolah Menengah Atas Negeri 1 Sidoarjo yang telah memberikan izin sehingga dapat terlaksananya penelitian ini, adik-adik siswi Sekolah Menengah Atas Negeri 1 Sidoarjo yang telah bersedia menjadi responden dalam penelitian ini, dan temanteman saya yang telah bersedia untuk membantu dalam penelitian ini. 


\section{REFERENSI}

1. Bardosono, S. Masalah Gizi di Indonesia. Maj. Kedokt. Indones. 59, 491-494 (2009).

2. Brown, J. E., Isaacs, J., Krinke, B., Lechtenberg, E. \& Murtaugh, M. Nutrition Through the Life Cycle. (Cengage Learning, 2013).

3. Syahrir, N. Pengetahuan Gizi, Body Image, dan Status Gizi Remaja di SMA Islam Athirah Kota Makassar Tahun 2013. (Universitas Sam Ratulangi, 2013).

4. Nurhaedar, J. Perilaku Gizi Seimbang Pada Remaja. Skripsi. Makassar: Universitas Hasanuddin, 2012. (Universitas Hasanuddin, 2012).

5. Arisman. Buku ajar ilmu gizi dalam daur kehidupan. (EGC Penerbit Buku Kedokteran, 2010).

6. Cash, T. F., Smolak, L. Body Image, Second Edition: A Handbook of Science, Practice, and Prevention. (Guilford Publications, 2011).

7. Arisman. Buku ajar ilmu gizi dalam daur kehidupan. (EGC Penerbit Buku Kedokteran, 2009).

8. Widyastuti, Y., Rahmawati, A., Purnamaningrum, Y. Kesehatan Reproduksi. (Fitramaya, 2009).

9. Restuti, A. N. \& Susindra, Y. Hubungan antara Asupan Zat Gizi dan Status Gizi dengan Kejadian Anemia pada Remaja Putri di SMK Mahfilud Durror II Jelbuk. in Seminar Hasil Penelitian dan Pengabdian Masyarakat Dana BOPTN Tahun 2016 74-80 (2016).

10. Stuart, G. Buku saku keperawatan jiwa. (EGC Penerbit Buku Kedokteran, 2009).

11. Jones, D. Body Image Among Adolescent Girls and Boys: A Longitudinal Study. Dev. Psychol. 40, 823-835 (2004).

12. Widianti, N., Candra, A. Hubungan antara body image dan perilaku makan dengan status gizi remaja putri di sma theresiana semarang. J. Nutr. Coll. 1, 398-404 (2012).

13. Almatsier, S. Prinsip dasar ilmu gizi. (Gramedia Pustaka Utama, 2009).

14. Sorhaindo, A., Feinstein, L. Relationship between child nutrition and school outcomes. (Center for Research on the Wider Benefits of Learning Institute of Education, 2006).

15. Cahyaningrum, H. Hubungan antara body image dengan status gizi pada remaja putri kelas XI IPS di SMA Batik Surakarta. (Universitas Muhammadiyah Surakarta, 2013).

16. Pujiati., Arneliwati., Rahmalia, S. Hubungan antara Perilaku Makan dengan Status Gizi pada Remaja Putri. J. Online Mhs. 7, 12-21 (2015).

17. Johnson, F., Wardle, J. \& Griffith, J. The Adolescent Food Habits Checklist: reliability and validity of a measure of healthy eating behaviour in adolescents. Eur. J. Clin. Nutr. 56, 644 (2002).

18. Cooper, P.J., Taylor, M.J., Cooper, Z., Fairburn, C. The development and validation of the body shape questionnaire. Int. J. Eat. Disord. 6, 485494 (1987).

19. Matthys, C., De Henauw, S., Bellemans, M., De Maeyer, M. \& De Backer, G. Breakfast habits affect overall nutrient profiles in adolescents. Public Health Nutr. 10, 413-421 (2007).

20. Sayogo. Gizi dan pertumbuhan remaja. (Fakultas Kedokteran Universitas Indonesia, 2006).

21. Šivert, Š. Š. \& Sinanović, O. Body dissatisfaction: Is age a factor? Philos. Sociol. Psychol. Hist. 7, 55-61 (2008).

22. Mahan, L.K., Stump, S. Krausers's food, nutrition, and diet therapy. (Saunders, 2008).

23. Marie Modestine, K. S. O. P., Inocent, G., Tetanye, E. \& H Amvam Zollo, P. Nutritional status, food habits and energy profile of young adult Cameroonian university students. (2018).

24. Kusumajaya, N, A, Wiardani, N.K., Juniarsana, I. Persepsi Remaja terhadap Body Image Kaitannya dengan Pola Konsumsi Makan. J. Skala Husada 5, 114-125 (2008).

25. Sada, M., Hadju, V. \& Dachlan, D. M. Hubungan Body Image, Pengetahuan Gizi Seimbang, dan Aktifitas Fisik 
terhadap Status Gizi Mahasiswa Politeknik Kesehatan Jayapura. Media Gizi Masy. Indones. 2, 44-48 (2012).

26. Laus, M., Laus, M. F., Souza, M. G., Moreira, R. de C. M. \& Braga-Costa, T. M. Body image dissatisfaction, nutritional status, and eating attitudes in adolescents. Acta Sci. Heal. Sci. 35, 243-247 (2013). 